\title{
INFLUÊNCIA DA MANUTENÇÃO DOS EQUIPAMENTOS DE REFRIGERAÇÃO NO DESEMPENHO ESCOLAR DE DOCENTES E DISCENTES DE ESCOLAS EM
} SÃO LUÍS-MA

\author{
Thymisson Sousa da Paixao ${ }^{1}$ \\ Adriano do Amor Divino Guilhon Serra ${ }^{2}$ \\ Antônio Vinicius Carvalho dos Santos ${ }^{3}$ \\ Noely Cristina Ferreira da Silva ${ }^{4}$ \\ Bianca Feques Vale Nantes ${ }^{5}$ \\ Josué Alves Rodrigues Junior ${ }^{6}$ \\ Paulo Roberto Campos Flexa Ribeiro Filho ${ }^{7}$
}

\begin{abstract}
RESUMO: A ausência do conforto térmico influencia diretamente os níveis de concentração de alunos e professores, acarretando consequências como a diminuição do desempenho e da produtividade. Neste contexto, a climatização dos locais de aprendizagem tornou-se essencial para melhorar os índices de educação do Ensino Médio, sobretudo nos estados do Nordeste nos quais as temperaturas podem alcançar médias anuais de vinte e oito graus. Desta forma, os equipamentos utilizados na refrigeração devem estar em boas condições de funcionamento para que, além de garantir conforto térmico, não prejudiquem a saúde dos docentes e discentes. Sendo assim, a manutenção desses equipamentos por meio da elaboração de planos periódicos serve para garantir o conforto térmico com eficiência energética. Por consequência, este trabalho tem como objetivo avaliar a condição dos equipamentos de refrigeração de três escolas de nível médio em São Luís, por meio da metodologia de elaboração de estratégias de manutenção, bem como da aplicação de questionários para avaliar a influência do conforto térmico no desempenho e produtividade dos envolvidos. Após a estruturação da manutenção dos equipamentos e, consequentemente, melhoria das condições de conforto térmico, observouse que para $76 \%$ dos alunos entrevistados houve melhora no desempenho dos professores; para $83 \%$ dos alunos houve melhoria de sua produtividade; e para 98\% houve melhoria da concentração em sala de aula.
\end{abstract}

Palavras-chave: Condicionador de ar; Conforto térmico; Plano de manutenção.

\section{INFLUENCE OF MAINTENANCE ON AIR-CONDITIONING EQUIPMENT ON THE PERFORMANCE OF TEACHERS AND STUDENTS ON SCHOOLS FROM SAO LUÍS, MA}

\begin{abstract}
The absence of thermal comfort directly influences concentration levels of students and teachers, resulting in consequences such as decreased performance and productivity. In this context, the climatization of the learning places became essential to improve the education indexes of high school, especially in the Northeast states, where the temperatures can reach yearly averages of 28 degrees Celsius. This way, the equipment used in

\footnotetext{
${ }^{1}$ Universidade Estadual do Maranhão - Curso de Engenharia Mecânica

${ }^{2}$ Departamento de Engenharia Mecânica e Produção. Área: Térmicas e Fluidos.

${ }^{3}$ Departamento de Engenharia Mecânica e Produção. Área: Térmicas e Fluidos.

${ }^{4}$ Departamento de Engenharia Mecânica e Produção. Área: Térmicas e Fluidos.

${ }^{5}$ Departamento de Engenharia Mecânica e Produção - Universidade Estadual do Maranhão.

${ }^{6}$ Departamento de Engenharia Mecânica e Produção - Universidade Estadual do Maranhão.

${ }^{7}$ Departamento de Engenharia Mecânica e Produção - Universidade Estadual do Maranhão.
} 
the air-conditioning must be in good working condition, besides guaranteeing the thermal comfort not to harm the health of teachers and students. Therefore, the structuring of the maintenance for these equipments through the elaboration of periodic plans serves to guarantee thermal comfort with energy efficiency. The objective of this study was to evaluate the condition of air-conditioning equipment on three high schools in São Luís through the methodology of elaborating maintenance strategies, as well as the application of questionnaires to evaluate the influence of thermal comfort on performance and productivity of those involved. After structuring the maintenance of the equipment with consequent improvement of the thermal comfort conditions, it was observed that for $76 \%$ of the students interviewed there was an improvement in the teachers performance, $83 \%$ of the students had an improvement of their productivities and for $98 \%$ of them there was improvement in the concentration on classroom.

Keywords: Air-conditioner; Thermal comfort; Maintenance plan.

\section{INTRODUÇÃO}

O conforto térmico trata-se de uma condição em que um ser humano não sente nem frio nem calor e está intimamente relacionado à capacidade de aprendizado no ambiente escolar. Isso porque, segundo Silva (2001), em um recinto refrigerado a aprendizagem é maximizada e a fadiga se desenvolve com velocidade menor.

Por tal motivo é que atualmente as instituições de ensino utilizam aparelhos de arcondicionado a fim de manter as salas de aulas em temperaturas confortáveis aos estudantes. A refrigeração das salas de aulas se torna mais importante nos estados do Nordeste, nos quais as temperaturas chegam aos quarenta graus e os índices de desenvolvimento da educação básica para o ensino médio, em 2013, alcançaram nota de 3,3 numa escala de zero a dez (INEB, 2013).

Como todo sistema mecânico, os aparelhos de refrigeração de ar precisam de manutenção para o seu bom funcionamento. Nesse cenário, tornam-se necessários o desenvolvimento e a estruturação de um setor de manutenção nas escolas a fim de definir as estratégias de manutenção corretas para administrar, visando à redução de custos e à qualidade da refrigeração do ar (VIANA, 2002).

Para Taylor (1995), a administração adquiriu novas atribuições e responsabilidades descritas por quatro princípios: Princípio de Planejamento (substituir a improvisação pela ciência, por meio do planejamento do método); Princípio de Preparo (preparo da mão de obra e máquinas/equipamentos de produção); Princípio do Controle (controlar o trabalho para se certificar de que está sendo executado de acordo com as normas estabelecidas e segundo o plano previsto); e Princípio da Execução (distribuir distintamente as atribuições e as responsabilidades para que a execução do trabalho seja bem mais disciplinada).

Revista Extensão em Foco, nº 17, Out./ Dez. (2018), p. 54 - 71 
Segundo Hamzah et al. (2014), a manutenção em sistemas de ar-condicionado é extremamente necessária à saúde, à economia e ao aumento da vida útil do equipamento. Como o ar-condicionado fica instalado em um ambiente fechado, está exposto ao acúmulo de poeira, que pode obstruir filtros, turbinas e serpentinas, diminuindo, assim, a eficiência da máquina.

Segundo Haverinen-Shaughnessya et al. (2015), a poeira que se acumula nos filtros do ar-condicionado volta ao ar à medida que o aparelho é utilizado. Esta poeira pode conter fungos, bactérias e outros poluentes, causando problemas alérgicos, dores de cabeça e ressecamento da pele.

Desta forma, é possível perceber que a falta de um setor bem estruturado de manutenção de arcondicionado nas escolas pode acarretar problemas de saúde às pessoas expostas a ele.

A manutenção também auxilia no aumento da vida útil dos equipamentos. Isso porque a manutenção preventiva dos sistemas de refrigeração atua antes da ocorrência da falha, podendo detectar problemas como enferrujamento e corrosão de peças, que são muito comuns em cidades litorâneas, como São Luís (FILHO, 2008).

Outro ponto importante alcançado com a manutenção de aparelhos de ar-condicionado é a economia de energia na medida em que aparelhos sem manutenção exigem mais dos compressores, o que gera maior consumo de energia.

A Agência Nacional de Vigilância Sanitária (ANVISA) fiscaliza a existência de manutenção de sistemas de ar-condicionados e exige testes periódicos nesses aparelhos em locais públicos, com grande circulação de pessoas. Esses testes devem ser feitos pela vigilância sanitária dos municípios para comprovar que o ar não está contaminado. E a multa em caso de falta de manutenção pode chegar a duzentos mil reais.

Desta forma, a estruturação da manutenção em sistema de ar-condicionado mostra-se extremamente necessária à garantia de saúde, à economia de energia e à melhoria do aprendizado nas escolas.

Sendo assim, este trabalho visa, por meio da avaliação das condições de conforto térmico de escolas da rede estadual, a criar e a aparelhar o setor de manutenção por meio da criação de planos de manutenção corretiva, preventiva, preditiva e rotinas de inspeção, a fim de melhorar as condições de aprendizagem.

\section{METODOLOGIA}

Revista Extensão em Foco, nº 17, Out./ Dez. (2018), p. 54 - 71 
É notório que o conforto térmico nas escolas públicas não é tratados como prioridade. A falta de salas arejadas e confortáveis termicamente influenciam na motivação e concentração dos alunos. Desta forma, em um ambiente escolar é necessário levar em conta a comodidade física dos estudantes com o proposito de favorecer o processo de ensino e aprendizagem (Nogueira e Nogueira, 2003).

Como crianças e adolescentes passam a maior parte do dia nas escolas, é de importância relevante o fornecimento de ambientes convenientes para que possam desempenhar suas atividades de forma adequada (Janesch, 2013). Por este motivo foram selecionadas três escolas da rede estadual do Maranhão, situadas no município de São Luís, identificadas como escolas A, B e C. Após a escolha das escolas foram realizadas visitas para identificar quais e quantos equipamentos de refrigeração existiam nas instituições. No levantamento dos aparelhos foram identificados as marcas e os modelos a fim de realizar a localização dos manuais de operação e manutenção junto aos fabricantes. A partir dos manuais coletou-se as recomendações de manutenção e inspeção dos equipamentos, informações que foram utilizadas para a determinação da estratégia de manutenção a ser adotada nas escolas.

Utilizando a metodologia de Márquez et al. (2009), definiu-se a estratégia de manutenção dos equipamentos. Em seguida, foram elaborados os planos de manutenção dos equipamentos individualmente, sendo contempladas atividades preventivas e preditivas.

A atividade de manutenção preventiva irá prever substituições e intervenções nos equipamentos; a manutenção preditiva utilizará as atividades de inspeção baseada em check list para identificar falhas antes que elas aconteçam.

Em seguida, a partir da metodologia de VIANA (2002), elaborou-se uma ferramenta para atendimento de manutenção corretiva, aquela que não pode ser identificada nas inspeções e que não foi eliminada nas manutenções preventivas. Será desenvolvido um fluxograma mostrando como a solicitação poderá ser feita e qual caminho percorrerá até ser atendida.

Para entendimento do processo de ensino-aprendizagem utilizou-se a metodologia de observação não participativa, que segundo Gil (2008) é o método onde os sujeitos não sabem que estão sendo observados, o observador não está envolvido na situação e não interege com o observado. O procedimento de observação foi aplicado a trinta e quatro turmas distribuídas da seguinte forma: desseseis turmas na escola $\mathrm{A}$, oito turmas na escola $\mathrm{B}$ e quatorze turmas na escola C. As observações foram realizadas em três momentos, uma aula no início do período 
letivo, uma aula após sessenta dias de aula e outra a cem dias de aula para a disciplina de matemática.

Após a estruturação da manutenção nas escolas, foi realizada pesquisa qualitativa por meio de questionário investigativo fechado, com aplicação da ferramenta de Google Formulários para avaliar a eficiência da estruturação dos planos de manutenção, além de analisar a influência do conforto térmico no rendimento de alunos e professores.

Os formulários foram aplicados à 2507 alunos das três escolas selecionadas, no período de maio e junho de 2017. Destes, 2255 alunos responderam ao questionário, representando $89,94 \%$ do universo. Os gráficos de apresentação dos resultados foram elaborados no Excel 2016.

Segue apresentado abaixo o questionário de cinco questões aplicado aos alunos:

$1^{\circ}$ ) Qual a sua avaliação sobre a aplicação do projeto da UEMA para estruturação da manutenção dos ar-condicionados de sua escola?

( ) Péssimo ( ) Ruim ( ) Regular ( ) Bom ( ) Ótimo

$2^{\circ}$ ) O desempenho dos professores melhorou com a aplicação do projeto de estruturação da manutenção dos aparelhos de refrigeração aplicados pela UEMA na sua escola?

( ) Sim ( ) Não

$3^{\circ}$ ) A sua produtividade nas aulas melhorou com a aplicação do projeto de estruturação da manutenção dos aparelhos de refrigeração aplicados pela UEMA na sua escola?

( ) Sim ( ) Não

$4^{\circ}$ ) A sua concentração nas aulas melhorou com a aplicação do projeto de estruturação da manutenção dos aparelhos de refrigeração aplicados pela UEMA na sua escola?

( ) $\operatorname{Sim}($ ) Não

$5^{\circ}$ ) Após a aplicação do projeto de estruturação da manutenção de aparelhos de refrigeração aplicados pela UEMA na sua escola, o conforto térmico está:

( ) Péssimo ( ) Ruim ( ) Regular ( ) Bom ( ) Ótimo

\section{RESULTADOS E DISCUSSÕES}

Após as visitas, realizou-se o inventário dos climatizados de ar de cada escola, representados nas tabelas 1, 2 e 3, respectivamente das escolas A, B e C, com as seguintes informações: local que o equipamento se encontra; quantidade; marca e modelo, para consulta nos manuais 
técnicos; capacidade térmica $(\mathrm{Btu} / \mathrm{h})$; tempo de funcionamento e existência algum tipo de manutenção.

Tabela 1 - Inventário da Escola A

\begin{tabular}{cccccc}
\hline Local & Quantidade & Marca & $\begin{array}{c}\text { Capacidade } \\
\text { Btu/h }\end{array}$ & $\begin{array}{c}\text { Tempo em } \\
\text { funcionamento }\end{array}$ & Manutenção \\
\hline Salas de Aula & 16 & Samsung & 18000 & 6 meses & N/A \\
Laboratório & 2 & Carrier & 36000 & 6 meses & N/A \\
Biblioteca & 2 & Samsung & 18000 & 6 meses & N/A \\
Salas da direção & 1 & LG & 18000 & 2 anos & N/A \\
Sala dos & 1 & LG & 18000 & 2 anos & N/A \\
professores & & & & & N/A \\
Secretaria & 1 & LG & 18000 & 6 meses & N/A \\
Auditório & 2 & Carrier & 36000 & &
\end{tabular}

Fonte: O Autor (2018)

Tabela 2 - Inventário da Escola B

\begin{tabular}{cccccc}
\hline Local & Quantidade & Marca & $\begin{array}{c}\text { Capacidade } \\
\text { Btu/h }\end{array}$ & $\begin{array}{c}\text { Tempo em } \\
\text { funcionamento }\end{array}$ & Manutenção \\
\hline Salas de Aula & 8 & Carrier & 36000 & 1 ano & 6 meses \\
Laboratório & 1 & Carrier & 36000 & 1 ano & 6 meses \\
Biblioteca & 1 & Segton & 18000 & 1 ano & 6 meses \\
Salas da direção & 1 & Carrier & 18000 & 1 ano & 6 meses \\
Sala dos & 1 & Carrier & 18000 & 1 ano & 6 meses \\
professores & & Segton & 18000 & 1 ano & 6 meses \\
Secretaria & 1 & Segron
\end{tabular}

Fonte: O Autor (2018)

Tabela 3 - Inventário da Escola C

\begin{tabular}{|c|c|c|c|c|c|}
\hline Local & Quantidade & Marca & $\begin{array}{c}\text { Capacidade } \\
\text { Btu/h } \\
\end{array}$ & $\begin{array}{c}\text { Tempo em } \\
\text { funcionamento }\end{array}$ & Manutenção \\
\hline Salas de Aula & 14 & Carrier & 36000 & 6 meses & $\begin{array}{l}\text { Limp. de } \\
\text { Filtro }\end{array}$ \\
\hline Laboratório & 1 & Carrier & 36000 & 1 ano & $\begin{array}{l}\text { Limp. de } \\
\text { Filtro }\end{array}$ \\
\hline Biblioteca & 1 & Consul & 18000 & 1 ano & Limp. de \\
\hline
\end{tabular}

Revista Extensão em Foco, nº 17, Out./ Dez. (2018), p. 54 - 71 


\begin{tabular}{cccccc} 
Salas da direção & 1 & LG & 18000 & 1 ano & $\begin{array}{c}\text { Filtro } \\
\text { Limp. de } \\
\text { Filtro }\end{array}$ \\
$\begin{array}{c}\text { Sala dos } \\
\text { professores } \\
\text { Secretaria }\end{array}$ & 1 & LG & 18000 & 1 ano & $\begin{array}{c}\text { Limp. de } \\
\text { Filtro } \\
\text { Limp. de } \\
\text { Filtro }\end{array}$ \\
\hline
\end{tabular}

Fonte: O Autor (2018)

A partir do levantamento foi possível constatar que a escola A não realiza nenhum tipo de manutenção nos equipamentos. Essa condição, além de gerar consumo de energia elevado, gera aumento das concentrações de dióxido de carbono e de poeira, causando maior possibilidade de alergia e asma (MI et al., 2002; SAHLBERG et al., 2002). Por sua vez, o desenvolvimento de problemas de saúde ocasionados pela falta de manutenção gera diminuição na concentração dos alunos e dos professores, influenciando seus rendimentos acadêmicos.

Além disso, a escola B não possui atividades definidas para as manutenções, que acontecem a cada seis meses. A escola $\mathrm{C}$ faz apenas uma atividade de manutenção, independentemente do período de utilização dos equipamentos, que acarreta perdas de rendimento, problemas de qualidade do ar e retrabalhos (GARCIA, 2017).

Durante processo de análise dos aparelhos das escolas, tivemos a oportunidade de notar vários problemas com as máquinas, principalmente na instalação e nas condições de funcionamento. Nas figuras 1, 2, 3, e 4 observamos as principais ocorrências encontradas.

Figura 1 - Filtro sujo, obstruindo a passagem de ar



Fonte: O Autor (2018)

Revista Extensão em Foco, nº 17, Out./ Dez. (2018), p. 54 - 71 
Na figura 1, nota-se a sujeira do filtro de ar, que impede a entrada de ar limpo no exaustor, aumentando a necessidade de potência e, por consequência, aumentando o consumo de energia (AHMED, 2017).

A Figura 2 mostra a comparação entre dois filtros: o da esquerda apresenta grau de contaminação elevado devido ao não atendimento da recomendação do fabricante acerca da manutenção a cada 7 dias; o da direita evidencia como deveria estar o filtro caso as recomendações fossem atendidas.

Figura 2- Comparação entre um filtro sujo (esquerda) e o filtro limpo (direita)

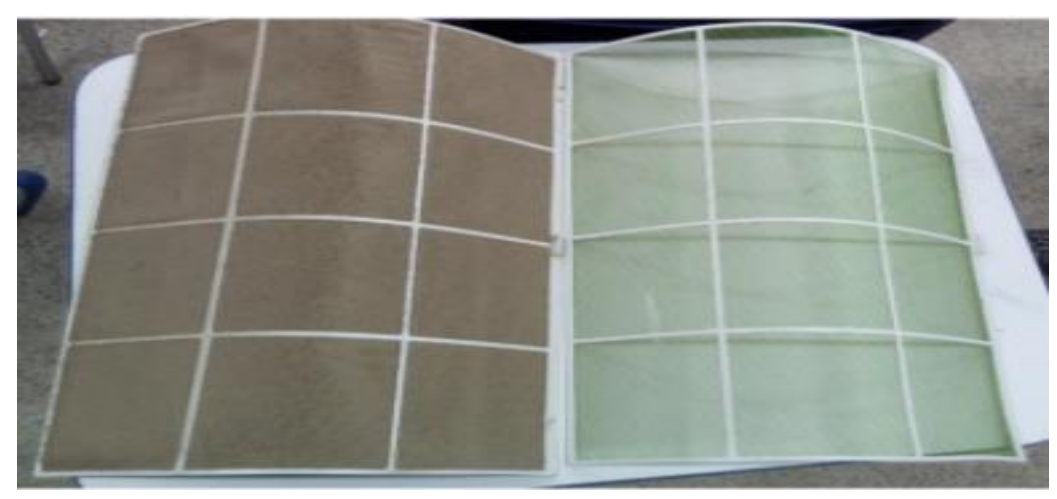

Fonte: O Autor (2018)

Na figura 3, observa-se a utilização inadequada de mangueira, o que acaba obstruindo a passagem da água, causando, assim, corrosão e comprometimento da bandeja.

Figura 3 - Equipamento com o dreno obstruído 


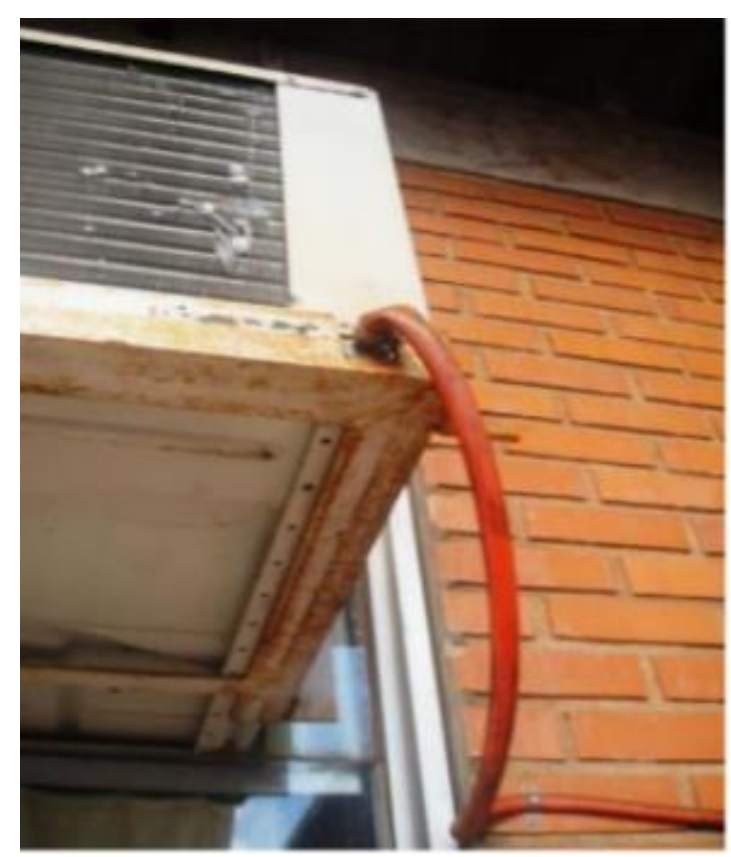

Fonte: O Autor (2018)

Na figura 4, observa-se o ar-condicionado funcionando com a vedação ambiente inadequada ou inexistente, aumentando a troca de calor com o meio externo.

Figura 4 - Ar-condicionado funcionando em ambiente com vedação ambiente inadequada
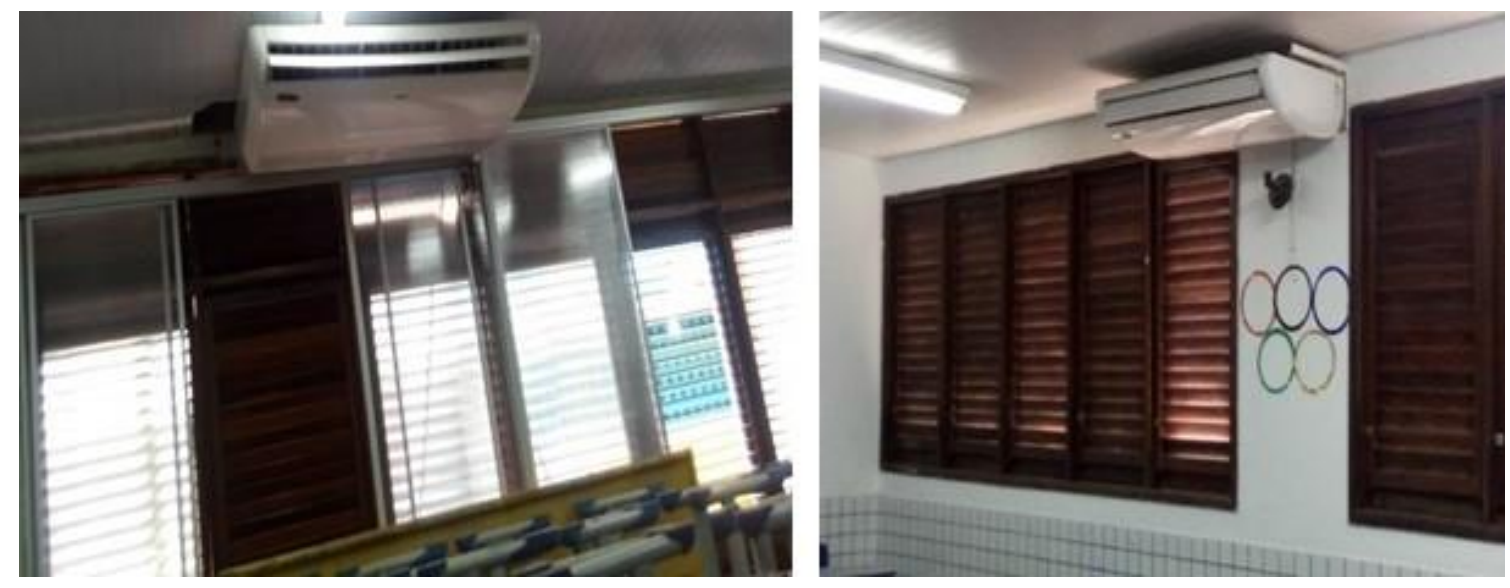

Fonte: O Autor (2018)

A partir de alguns estudos (LG, 2018; CARRIER, 2018; CONSUL, 2008; SAMSUNG, 2000; SEGTRON, 2018) elaborou-se um check list para acompanhamento das atividades com o objetivo de realizar melhor gerenciamento da manutenção dos equipamentos.

O quadro 1 sobre acompanhamento das manutenções pode visto abaixo:

Revista Extensão em Foco, nº 17, Out./ Dez. (2018), p. 54 - 71 
Quadro 1 - Check list de Acompanhamento da Manutenção

\begin{tabular}{|c|c|c|c|c|}
\hline Descrição da atividade & Periodicidade & $\begin{array}{l}\text { Data de Próxima|I } \\
\text { Execução execução }\end{array}$ & $\begin{array}{l}\text { Executado } \\
\text { por }\end{array}$ & $\begin{array}{l}\text { Aprovado } \\
\text { Por }\end{array}$ \\
\hline $\begin{array}{l}\text { Eliminar sujeira, danos e corrosão } \\
\text { no gabinete }\end{array}$ & & & & \\
\hline $\begin{array}{l}\text { Eliminar sujeira, danos e corrosão } \\
\text { na bandeja }\end{array}$ & & & & \\
\hline $\begin{array}{l}\text { Eliminar sujeira, danos e corrosão } \\
\text { na serpentina }\end{array}$ & & & & \\
\hline $\begin{array}{l}\text { Verificar a operação de } \\
\text { drenagem de água da bandeja }\end{array}$ & & & & \\
\hline $\begin{array}{l}\text { Verificar o estado de conservação } \\
\text { do isolamento termo-acústico }\end{array}$ & & & & \\
\hline $\begin{array}{l}\text { Verificar a vedação dos painéis } \\
\text { de fechamento do gabinete }\end{array}$ & & & & \\
\hline Verificar os filtros de ar & & & & \\
\hline $\begin{array}{l}\text { Limpar (quando recuperável) ou } \\
\text { substituir (quando descartável) o } \\
\text { elemento filtrante }\end{array}$ & & & & \\
\hline $\begin{array}{l}\text { Verificar e eliminar as obstruções } \\
\text { no retorno e tomada de ar externo }\end{array}$ & & & & \\
\hline Verificar as fixações & & & & \\
\hline Medir o diferencial de pressão & & & & \\
\hline $\begin{array}{l}\text { Verificar os componentes } \\
\text { eletrônicos }\end{array}$ & & & & \\
\hline $\begin{array}{l}\text { Questionar os usuários sobre } \\
\text { sujeira, odores desagradáveis, } \\
\text { fontes de ruídos, infiltrações, } \\
\text { geração de Micro-organismos }\end{array}$ & & & & \\
\hline
\end{tabular}

Fonte: O Autor (2018)

Estabeleceu-se um fluxograma de tomada de decisão baseado em Viana (2002) para auxiliar a direção da escola sobre qual caminho tomar em certas situações, como, por exemplo, quando for diagnosticada manutenção corretiva, aquela que acontece de forma inesperada, e quando não houver possibilidade de planejar a mão de obra, a compra de recursos para o restabelecimento do funcionamento dos equipamentos e até mesmo a negociação da interrupção das aulas. A figura 5 apresenta o fluxograma elaborado.

Revista Extensão em Foco, nº 17, Out./ Dez. (2018), p. 54 - 71 
Figura 5 - Fluxograma para manutenção corretiva

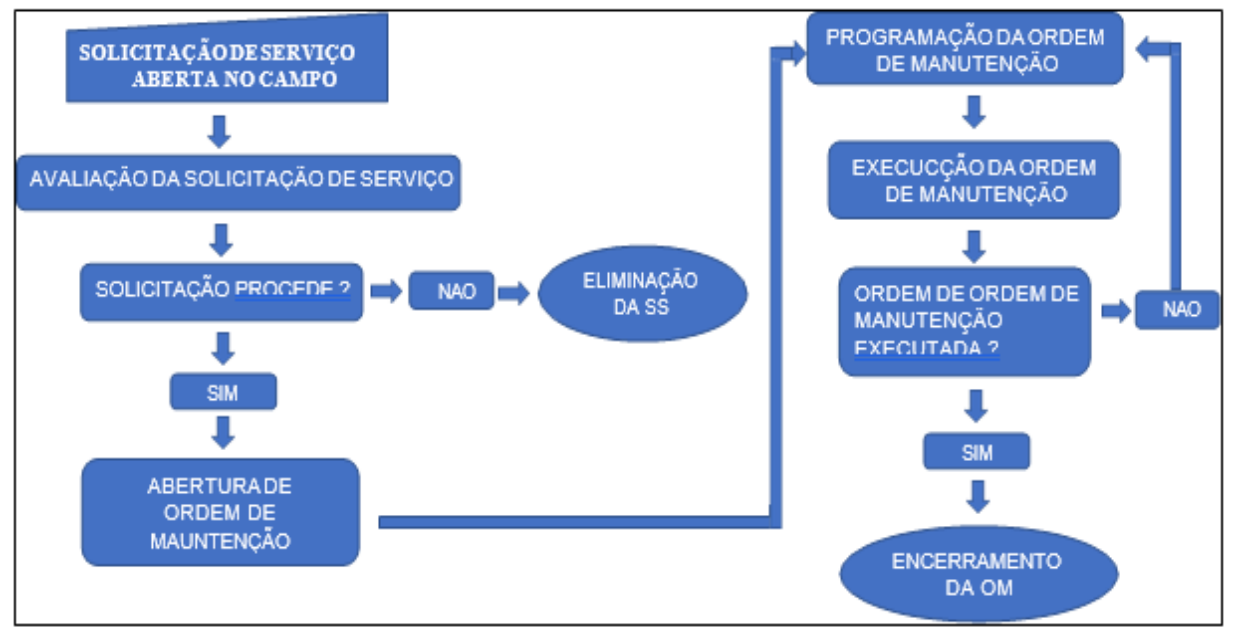

Fonte: O Autor (2018)

O fluxograma da figura 5 apresenta a metodologia para execução de serviços de manutenção corretiva. Com esse método é possível corrigir qualquer erro durante o processo, garantindo, assim, que o resultado final seja o melhor possível.

A primeira etapa é abrir a ordem de serviço quando o problema for detectado. O próximo passo é avaliação da solicitação de serviço, etapa que pode ser executada por técnicos responsáveis e, se o problema não for detectado, a solicitação de serviço é eliminada, mas, caso seja comprovado o problema, o fluxograma recomenda a abertura de ordem de manutenção e, em seguida, que se estabeleça a programação de execução do serviço. O próximo passo é saber se a ordem de manutenção foi executada corretamente, avaliando a qualidade do serviço realizado e, se a resposta for sim, a ordem de serviço será encerrada.

Para a manutenção preventiva, elaborou-se o plano de manutenção que é, basicamente, ação planejada e sistemática de tarefas de prevenção com intervalos previamente estabelecidos e que envolve programas de inspeção, reformas, reparos, entre outros. Trata-se da monitoração de determinado equipamento estudado para evitar que apresente erros ou quebra inesperada.

No Quadro 2 apresentamos um dos planos de manutenção elaborados a partir das recomendações do fabricante, para o refrigerador de ar da marca Carrier ${ }^{\circledR}$, do modelo Split Space 42XQM. Esse quadro descreve os serviços que devem ser executados por um profissional técnico, sendo essenciais para acompanhar o desgaste da máquina e sendo possível determinar as condições de uso de vários componentes. Do lado direito temos a frequência em

Revista Extensão em Foco, nº 17, Out./ Dez. (2018), p. 54 - 71 
que cada serviço deve ser executado, sendo A para serviços em quinzenas, $\mathbf{B}$ para serviços mensais e $\mathbf{C}$ para serviços semestrais.

Quadro 2 - Plano de Manutenção Preventiva para o modelo CARRIER Split Space 42XQM

\begin{tabular}{|c|c|c|c|c|}
\hline \multirow[b]{2}{*}{ Item } & \multirow{2}{*}{\begin{tabular}{|l|} 
CARRIER Split Space 42XQM \\
Descrição dos Serviços
\end{tabular}} & \multicolumn{3}{|c|}{ Frequência } \\
\hline & & & B & $\mathbf{C}$ \\
\hline $1^{\mathrm{o}}$ & $\begin{array}{l}\text { Inspeção geral na instalação do equipamento, curto-circuito de ar, } \\
\text { distribuição de insuflamento nas unidades, bloqueio na entrada e saída } \\
\text { de ar do condensador, unidade condensadora exposta à carga térmica }\end{array}$ & & & $\mathrm{X}$ \\
\hline $2^{\circ}$ & Verificar instalação elétrica & $\mathrm{X}$ & & \\
\hline $3^{\circ}$ & Lavar e secar o filtro de ar & $\mathrm{X}$ & & \\
\hline $4^{\circ}$ & Medir tensão e corrente de funcionamento e comparar com a nominal & $X$ & & \\
\hline $5^{\circ}$ & $\begin{array}{l}\text { Medir tensão com rotor travado e observar queda de tensão até que o } \\
\text { protetor desligue }\end{array}$ & & $\mathrm{X}$ & \\
\hline $6^{\circ}$ & $\begin{array}{l}\text { Verificar aperto de todos os terminais elétricos das unidades e evitar } \\
\text { possíveis maus contatos }\end{array}$ & $\mathrm{X}$ & & \\
\hline $7^{\circ}$ & Verificar obstrução de sujeira e aletas amassadas & $\mathrm{X}$ & & \\
\hline $8^{\circ}$ & $\begin{array}{l}\text { Verificar possíveis entupimentos ou amassamentos na mangueira do } \\
\text { dreno. }\end{array}$ & $\mathrm{X}$ & & \\
\hline $9^{\circ}$ & Fazer limpeza dos gabinetes & & $\mathrm{X}$ & \\
\hline $10^{\circ}$ & Medir diferencial de temperatura & $\mathrm{X}$ & & \\
\hline $11^{\circ}$ & Verificar folga do eixo dos motores elétricos & $\mathrm{X}$ & & \\
\hline $12^{\circ}$ & Verificar posicionamento, fixação e balanceamento da hélice ou turbina & $X$ & & \\
\hline $13^{\circ}$ & Verificar operação do sensor de temperatura & $\mathrm{X}$ & & \\
\hline $14^{\circ}$ & Medir pressões de equilíbrio & & $\mathrm{X}$ & \\
\hline $15^{\circ}$ & Medir pressões de funcionamento & & $\mathrm{X}$ & \\
\hline
\end{tabular}

Fonte: O Autor (2018)

Revista Extensão em Foco, nº 17, Out./ Dez. (2018), p. 54 - 71 
O processo de ensino-aprendizagem da disciplina de matemática nas três escolas é na sua totalidade baseada em aulas expositivas, onde existe pouca ou nenhuma interação dos alunos com o professor. Fato corroborado por Vasconcellos (1992), que aponta existência de alto risco de não aprendizagem nas aulas expositivas pelo baixo nível de interação sujeito-objeto do conhecimento, o que provoca baixo interesse dos alunos e níveis de concentração insuficientes. Acrescenta ainda que está modalidade de aulas forma homens passivos e sem senso critico. Os baixos níveis de concentração podem ser majorados quando as condições de conforto térmico não são inadequadas.

Nos gráficos das figuras 6, 7, 8, 9 e 10 apresentamos os resultados alcançados com a aplicação do questionário.

Figura 6 - Gráfico da avaliação da iniciativa da aplicação do projeto

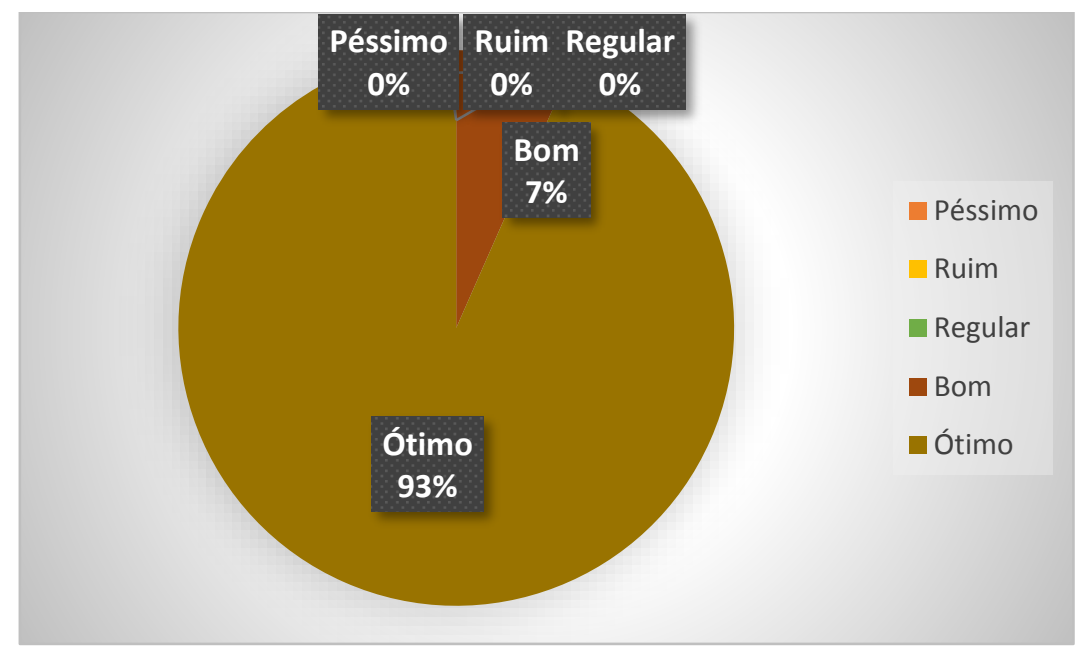

Fonte: O Autor (2018)

O gráfico da figura 6 mostra que, dos 2255 alunos que responderam o questionário, 2106 acreditam que a iniciativa do projeto é ótima (93\%) e 149 responderam que a iniciativa é boa $(7 \%)$.

Esses números comprovam a importância da extensão universitária nas comunidades, na medida em que a aplicação dos saberes desenvolvidos na academia serve para decodificar ao público a importância das universidades para o desenvolvimento social (NUNES; DA CRUZ SILVA, 2011).

O gráfico da figura 7 expõe que, para os 2255 alunos entrevistados, 1718 (76\%) responderam que a aplicação do projeto de estruturação dos sistemas de ar-condicionado melhorou o Revista Extensão em Foco, nº 17, Out./ Dez. (2018), p. 54 - 71 
desempenho dos professores, enquanto para 537 (24\%) o projeto não implicou alteração do desempenho dos alunos.

Figura 7 - Gráfico da avaliação do desempenho dos professores

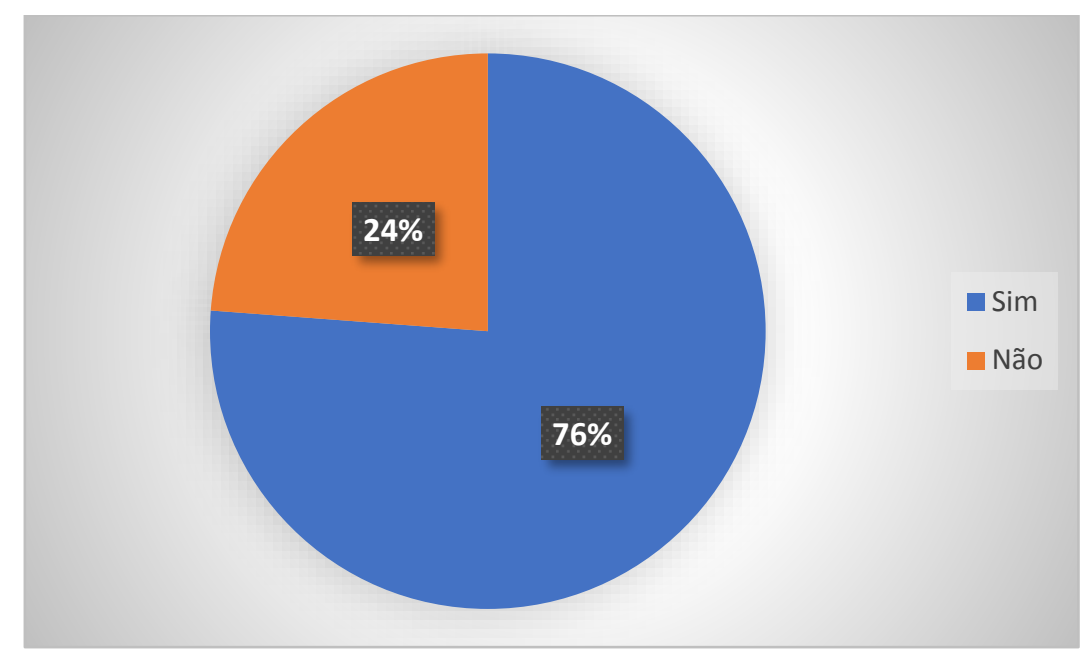

Fonte: O Autor (2018)

Conforme nos resultados alcançados no gráfico da figura 7 , a percepção dos alunos é confirmada, porque as elevadas temperaturas causam desconforto, que prejudica o aprendizado deles, por causar agitação, dor de cabeça e mau humor nos professores (MOURA et al.,2017). No gráfico da figura 8 observa-se o resultado para a pergunta relacionada ao aumento de produtividade dos alunos após a implementação do projeto de estruturação da manutenção nas escolas. Para 1868 (83\%) alunos, a execução do projeto de estruturação da manutenção dos climatizadores de ar aumentou a produtividade deles, enquanto 387 (17\%) alunos declararam que não houve alteração das suas produtividades em sala de aula.

Figura 8 - Gráfico da avaliação da produtividade dos alunos 


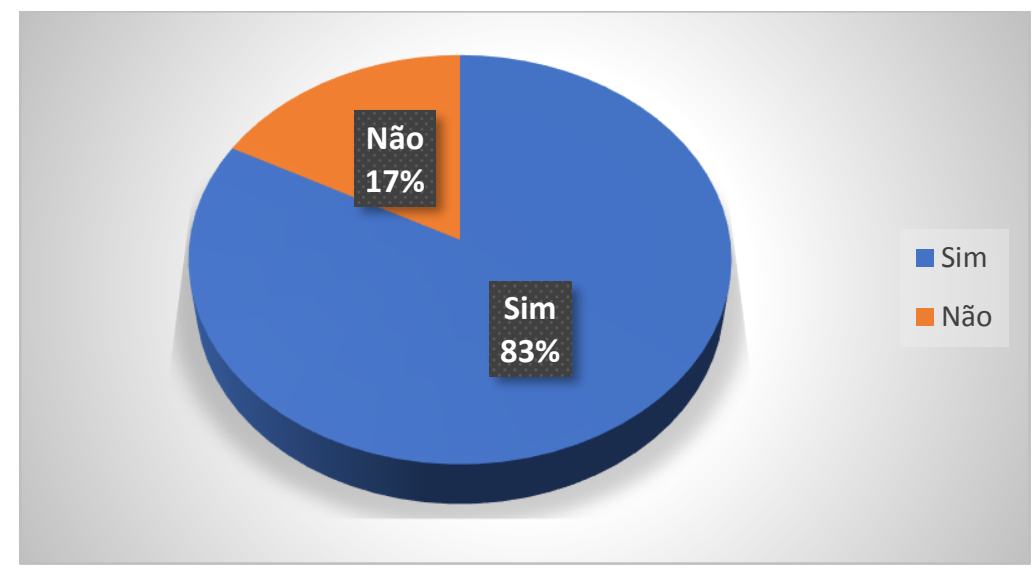

Fonte: O Autor (2018)

Os dados apresentados na figura 8 são coerentes. Isso por que, segundo Batiz (2009), as condições térmicas influenciam a percepção e a memória dos alunos. Quando as condições de conforto térmico são favoráveis, há melhores condições para o aprendizado.

No gráfico da figura 9 observa-se o resultado para a pergunta relacionada à concentração dos alunos após a implementação do projeto de estruturação da manutenção nas escolas. Para 2205 (98\%) alunos, a execução do projeto aumentou a concentração deles, enquanto 50 (2\%) alunos declarou que não houve alteração das suas concentrações em sala de aula.

Figura 9 - Gráfico da avaliação da concentração dos alunos

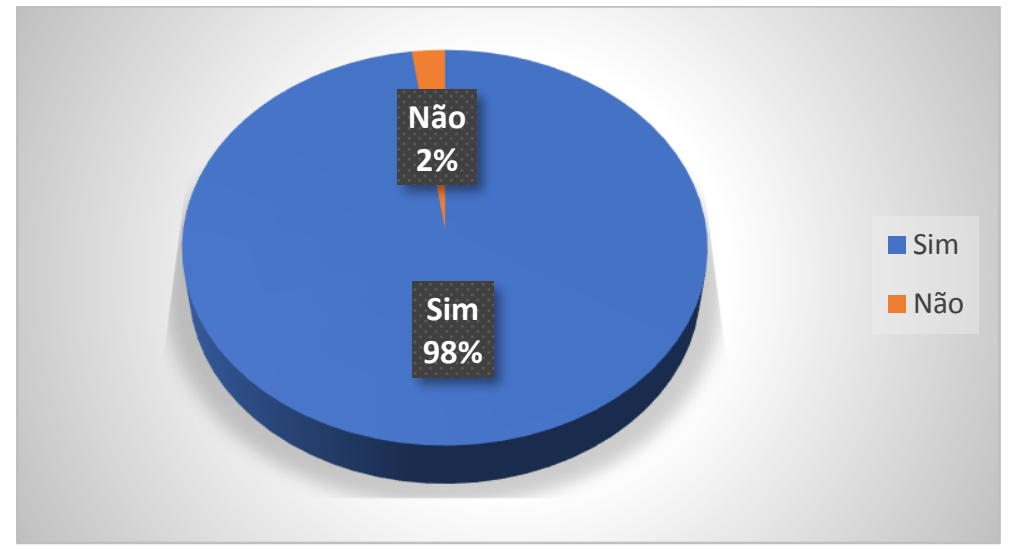

Fonte: O Autor (2018)

Os dados apresentados na figura 9 tem nexo, pois, segundo Kowaltowski et al. (2005), condições inadequadas de conforto térmico podem gerar prejuízos à concentração dos alunos. Além disso, a falta de conforto causa distração e cansaço, fatores que prejudicam o aprendizado e o rendimento dos alunos.

No gráfico da figura 10 observa-se o resultado para a pergunta relacionada ao conforto térmico dos alunos após a implementação do projeto de estruturação da manutenção nas escolas. Para Revista Extensão em Foco, nº 17, Out./ Dez. (2018), p. 54 - 71 
2049 (91\%) alunos, a execução do projeto aumentou o conforto térmico deles, enquanto 206 (9\%) alunos declararam que não houve alteração no conforto térmico em sala de aula.

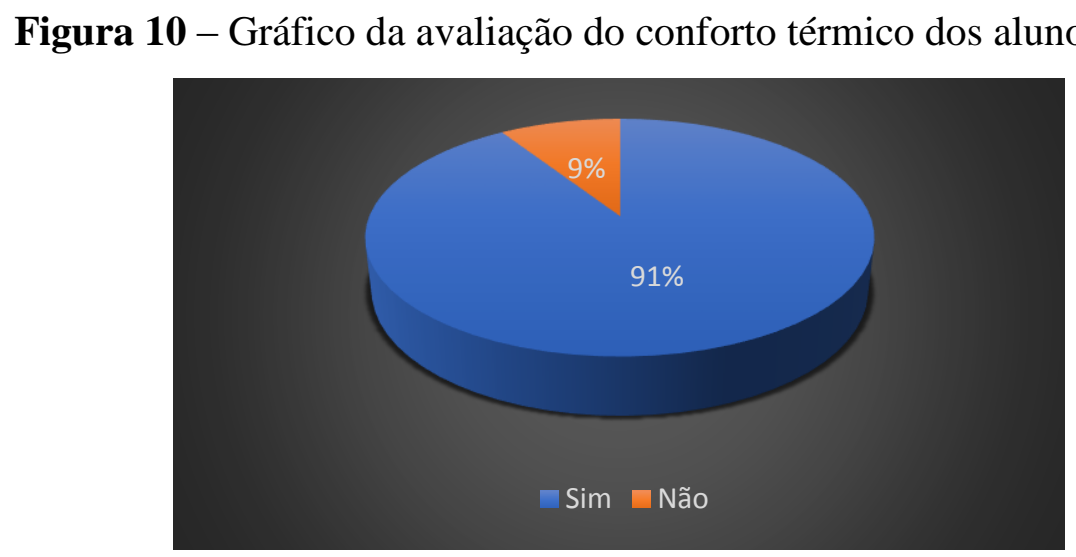

Fonte: O Autor (2018)

Os resultados apresentados na figura 10 são reforçados por Kowaltowski et al. (1999), que dizem que a falta de estratégia de manutenção dos equipamentos de refrigeração leva a problemas, principalmente relacionados à insolação direta sobre os alunos durantes as aulas, além da possibilidade de ofuscamento do quadro negro, o que pode provocar baixo desempenho dos alunos.

\section{CONSIDERAÇÕES FINAIS}

A atividade de gerenciamento da manutenção de sistemas de refrigeração nas escolas é essencial para a garantia do perfeito funcionamento dos equipamentos. A definição de estratégias para as manutenções preventivas e corretivas auxiliam na tomada de decisão de diretores de escolas, que na sua maioria, não detém conhecimento técnico.

Além disso, é importante citar que é necessário que o setor responsável pela manutenção dos equipamentos das escolas contrate ao menos um funcionário qualificado para operar e realizar manutenção nos aparelhos de ar-condicionado, a fim de garantir as condições de conforto térmico, produtividade e concentração dos alunos.

O trabalho constatou que, apesar das escolas estudadas estarem equipadas com aparelho de refrigeração na totalidade de suas salas de aulas, a condição de funcionamento e manutenção dos equipamentos era precária, fato que atrapalhava substancialmente o desempenho de alunos e professores nas atividades escolares.

Revista Extensão em Foco, nº 17, Out./ Dez. (2018), p. 54 - 71 
A atividade extensionista deste trabalho, na opinião dos alunos, contribuiu para a melhoria do desempenho dos professores, aumento da produtividade, concentração e conforto térmico dos discentes.

\section{REFERÊNCIAS}

AHMED, Munir Omram. Proposta de metodologia para gestão de manutenção de um sistema frigorífico em um restaurante self service. 2017. 66 p. (Trabalho de Conclusão de Curso). Niterói/RJ, Universidade Federal Fluminense, UFF, 2017.

BATIZ, Eduardo Concepción et al. Avaliação do conforto térmico no aprendizado: estudo de caso sobre influência na atenção e memória. In: Production. São Paulo, v. 19, n. 3, p. 477-488, 2009.

CARRIER, Manual de instalação, operação e manutenção. Canoas, RS, 2018. Disponível em: <http://www.casadoar.com/download/splits/carrier/MANUAL-INSTALACAOCASSETTE-CARRIER.pdf> Acesso em: 10 jan. 2018.

CONSUL, Manual do Consumidor: condicionador de ar Split. Manaus, AM, 2008. Disponível em: <https://images.colombo.com.br/produtos/486252/486252_1406050292792.pdf> Acesso em: 10 jan. 2018.

FILHO, Rogério Arcuri. Introdução à Manutenção Centrada na Confiabilidade - MCC. Programa de Atualização Técnica 2008 - Sistema FIRJAN - SESI/SENAI - Rio de Janeiro [On line]. Disponível em < http://manutencao.net/v2/uploads/article/file/Artigo24AGO2008.pdf> Acesso em 11 out. 2017.

GARCIA, Fabiano Luiz. Proposta de Implantação de Manutenção Preventiva em um Centro de Usinagem Vertical: Um Estudo De Caso. Tecnologia e Tendências, v. 9, n. 2, p. 88-115, 2017.

GIL, Antonio Carlos. Métodos e técnicas de pesquisa social. 6. ed. Ediitora Atlas SA, 2008.

HAMZAH, B. et al. The Effect of Environmental Factors on the Thermal Comfort of Occupants in Building InteriorInternational Conferences on 15th SENVAR (Sustainable Environmental Architecture), Department of Architecture, Faculty of Engineering, Hasanuddin University. Anais...Makassar: 2014

HAVERINEN-SHAUGHNESSY, U. et al. Characterization of indoor environmental quality in schools and its association with health and performance. Building and Environment, v. 93, p. 35- 40, mar. 2015.

IDEB. Estatística do IDEB 2013. Disponível em: http://portal.inep.gov.br/web/portalideb/planilhas-para-download. Acesso em: 20 junho 2016.

JANESCH, Mônica. Educação infantil: a importância da iluminação e cor no desempenho e aprendizado da criança. Especialize 1-15, 2013.

Revista Extensão em Foco, nº 17, Out./ Dez. (2018), p. 54 - 71 
KOWALTOWSKI, Doris Catharine Cornelie Knatz. et al. Melhoria do conforto ambiental em edificações escolares na região de Campinas. ENCONTRO NACIONAL DE CONFORTO NO AMBIENTE CONSTRUÍDO, v. 2, 1999.

KOWALTOWSKI, Doris Catharine Cornelie Knatz et al. O conforto no ambiente escolar: elementos para intervenções de melhoria. IX Encontro Nacional de Tecnologia do Ambiente Construído, Foz do Iguaçu. Anais do ENTAC, p. 173-182, 2002.

LG, Manual do usuário Condicionador de Ar Split. Manaus, AM, 2018. Disponível em: <http://www.multiarplus.com.br/manuais/LG/Manual-LG-Convencional.pdf> Acesso em: 10 jan. 2018.

MÁRQUEZ, Adolfo Crespo. et al. The Maintenance Management Framework: a Practical View to Maintenance Management. Journal of Quality in Maintenance Engineering, v. 15, n. 2, p. 167-178, 2009.

MI, Y. H. et al. Indoor allergens in schools: A comparison between Sweden and China. In: 9 th International Conference on Indoor Air Quality and Climate, Proceedings. 2002. p. 449455 .

MOURA, Premma Hary Rodrigues et al. O CONFORTO AMBIENTAL DO PROFESSOR EM SALA DE AULA. PRODUÇÃ̃ ACADÊMICA, v. 2, n. 2, p. 98-114, 2017.

Nogueira, M. C. J. A. e Nogueira, J. S. (2003). Educação, meio ambiente e conforto térmico: caminhos que se cruzam. Revista Electrónica em Educação Ambiental, 10, 104-108.

NUNES, Ana Lucia de Paula Ferreira; DA CRUZ SILVA, Maria Batista. A extensão universitária no ensino superior e a sociedade. Mal-Estar e Sociedade, v. 4, n. 7, p. 119-133, 2011.

SAHLBERG, B.; SMEDJE, G.; NORBACK, D. Sick building syndrome (SBS) among school employees in the county of uppsala, Sweden. Indoor Air, 2002.

SAMSUNG, Manual do Usuário: Ar condicionado Samsung. Manaus, AM, 2000. Disponível em: <http://www.multiarplus.com.br/manuais/Samsung/Samsung-As-Aq.pdf> Acesso em: 10 jan. 2018.

SEGTRON, Manual de Uso e Manutenção: Ar condicionado Split. São Paulo, SP, 2018. Disponível em: <http://www.raldonar.com/usermanualportuguese.pdf> Acesso em: 10 jan. 2018.

SILVA, L. B. Análise da relação entre Produtividade e conforto térmico: o caso dos digitadores do centro de processamento de dados da Caixa Econômica Federal de Pernambuco. Florianópolis, 2001. Tese (Doutorado em Engenharia de Produção) Universidade Federal de Santa Catarina.

TAYLOR, Frederick W. Princípios da administração científica. São Paulo: Editora Atlas S.A., 1995.

VASCONCELLOS, Celso dos S. Metodologia dialética em sala de aula. Rev Educ AEC, v. 21, n. 83, p. 28-55, 1992.

VIANA, Herbert Ricardo Garcia. Planejamento e Controle da Manutenção. 1. ed. Rio de Janeiro: Qualitymark Ed., 2002.

Revista Extensão em Foco, nº 17, Out./ Dez. (2018), p. 54 - 71 